\title{
Colour, Culture and Deixis as Elements of Meaning in the Discourse of Advertising Mobile Telecommunications Networks in Nigeria
}

\author{
Adeyemi Adegoju \\ Department of English \\ Obafemi Awolowo University \\ Ile-Ife, Nigeria \\ yemiadegoju@oauife.edu.ng \\ yedegoju@yahoo.com
}

\begin{abstract}
This article examines the appropriation of sign systems in the discourse of marketing the services of mobile telecommunications networks in Nigeria. The paper attempts to interpret the sign systems deployed in these marketing strategies in relation to the contextual background within which they operate, revealing multiplicities of meaning that are tied to the service providers' ideological perceptions, which to a large extent appeal to the audience's sentiments and in some cases abuse their sensibilities.
\end{abstract}

\section{Introduction}

The Global System of Mobile Telecommunications (GSM) revolution in Nigeria's communications industry is arguably that coveted leveller which has enabled common citizens to share the experience of the elite, which had for a long time a privileged access to telephones. What the situation was prior to this watershed is captured thus:

Before now, many Nigerians had no hope or dream to own a phone as the service provider [...] NITEL [Nigerian Telecommunications Limited Plc] made things very difficult. One had to pass through lots of hurdles before getting a line. In fact, from the handwriting on the wall, it became very lucid to Nigerians that the telephone was not meant for the poor. ${ }^{1}$

Consequently, if ordinary Nigerian citizens were asked to reflect upon the singular reform of the Olusegun Obasanjo administration which touched their lives the most, they would not hesitate to cite the liberalization of Nigeria's telecommunications market as 'a true dividend of democracy'.

By February 2001, four firms - Econet Wireless (Nigeria), MTN, Communications Investment Limited (CIL) and NITEL had emerged as GSM licensed operators in the country. CIL was, however, refused a license by the Nigerian Communications Commission (NCC) on the grounds that it failed to meet the deadline for the payment of the license fee. In 2002, another service provider Globacom (an indigenous company) received its operational license and joined the race. Apart from these major networks, there are private telephone operators such as Starcomms, Oduatel, Mobitel, Multilinks, among others, that have been granted licenses.

Since 6 August 2001 when the first call was made on an Econet Wireless mobile phone in Nigeria, Nigeria's telecommunications industry has grown by leaps and bounds as affirmed in this comment:

\footnotetext{
${ }^{1}$ Quoted from a feature article 'Four Years of (GSM): The Journey So Far'. The Guardian. Vol. 22, No 9,772, Wednesday August 24, 2005.
} 
The transformation of Nigeria's telecommunications landscape since the licensing of three GSM networks in 2001 and a fourth one in 2002 has been nothing short of astounding. The country continues to be one of the fastest growing markets in Africa with triple-digit growth rates almost every single year since 2001. It passed Egypt and Morocco in 2004 to become the continent's second largest mobile market after South Africa. And yet it has only reached about one quarter of its estimated ultimate market potential. ${ }^{2}$

Interestingly, this sector of Nigeria's national life has generated stimulating discussions at seminars and workshops, in editorials and features in newspapers and magazines, in parliamentary sessions, as well as in informal exchanges among the general public. There are many advantages attributable to the remarkable turnaround in Nigeria's telecom industry. The advent of GSM has contributed to the increase in the gross domestic product (GDP) of the country, as the revolution has enhanced the efficiency of business transactions, saving people's time and energy that they would otherwise have expended on the road. Another major benefit of mobile telephony to the economy is the provision of employment opportunities to many Nigerians.

While acknowledging the relevance of these issues, this study explores the discourse of marketing GSM networks, since the frontiers of the advertising industry in Nigeria have been advanced so much that every imaginable outlet has been utilized for promoting the companies offering GSM services in Nigeria. Particularly striking is the GSM service providers' rhetorical style adopted to penetrate the Nigerian market. It is intriguing that the advertisers deploy seemingly ordinary objects, events, concepts, entities, situations and scenery in the audience's immediate environment to convey a deeper level of meaning in their advertisements. Writing generally on the style of such advertisements, McKeown (1998: 1) says: "The people behind the making of 'ads' are the transmitters and therefore are aware of the codes in operation within the culture they are working or living in. So advertising uses 'a system of distinct signs."”

Drawing upon this viewpoint, this paper examines the (re)construction of meaning through signs in the advertisements of mobile telecommunications networks in Nigeria. We will first need to provide some background information about the sample data in Section 2. In Section 3, we will discuss the role of connotation in semiotic analysis, while underscoring the place of the reader in the social production of meaning. Section 4 of the paper examines the factor of colour in branding GSM companies, while Section 5 discusses the semiotic force of verbal signs and cultural units in the advertisements. This is the order in which the rest of the article is organized, leading us to Section 6 which gives the concluding remarks.

\section{Sources of Data}

We have purposively sampled data from newspapers, magazines, radio and television jingles, and billboards. Structures such as houses, fences, kiosks and erect broad umbrellas, carrying the trademark of GSM service providers are also interesting sources of data for this study. Mass transit/luxury buses whose bodies are clad in GSM advertisements, souvenirs and bannerettes also provide rich sources of data. The sample data, though restricted, would be adequate for analysis in that there are parallels in the advertisements even where there are slight shifts in configurations across modes - written and spoken, on the one hand, and verbal and non-

\footnotetext{
${ }^{2}$ Cited from http://www.lxcomm.com/lx-telecommunications-research-toc.asp?toc=2998.
} 
verbal, on the other. It is noteworthy that such overlaps are functions of the ideological motivations for the advertisements which are a constant in the discourse.

\section{Theoretical Considerations}

How reality is organized and constructed, as well as how ideology and meanings are produced in the advertising discourse, is so intricate that the reader, in an attempt to process advertising meanings, cannot but appeal to the subtlety and power of connotation. With close reference to meaning interpretation in print advertisements, Leiss et al. (1990: 201-202) argue:

The semiological approach [...] suggests that the meaning of an ad does not float on the surface just waiting to be internalized by the viewer, but is built up out of the ways that different signs are organized and related to each other, both within the ad and through external references to wider belief systems. More specifically, for advertising to create meaning, the reader or viewer has to do some 'work'. Because the meaning is not lying there on the page, one has to make an effort to grasp it.

In the light of this argument, this paper applies the connotative semiotics framework to underpin and explain the semiotic import of verbal and visual signs in the advertisements of GSM networks in Nigeria.

'Connotation' is used to 'refer to the socio-cultural and 'personal' associations (ideological, emotional, etc.) of the sign. These are typically related to the interpreter's class, age, gender, ethnicity and so on" (Chandler, 1994a: 1). Although it is presumed that there is a code-sharing between the producer and the reader of a text that could maximize efficient and effective communication, connotation opens up the possibilities of meaning such that the reader could come up with diverse interpretations which depart from what the sender of the message originally intends. Borrowing from Schmidt's (1984) philosophical argument, Mick and Politi (1989: 7) submit that 'the interpretation of advertising is a subject-dependent, internal monologue through which consumers generate, change and maintain their individual reality'. It must be noted, however, that connotations are not purely 'personal' meanings, for they are determined by the code to which the interpreter has access. In this sense, Chandler (1994b: 5) cites Voloshinov (1973: 23) who referred to the 'multi-accentuality' of the sign, that is, the potential for diverse interpretations of the sign according to particular social and historical contexts.

This chance to uncover the playfulness of language brings to the fore the notion of 'oppositional reading' which gives room for multiplicities of meaning that audiences can choose to attach to a text while "searching for what is 'hidden' beneath the "obvious" (Chandler, 1994b: 2). This derives from the fact that the audience may have a very different cultural or social experience from the producer's and thus may connect signifiers to completely different signifieds. This approach to text reading is opposed to the notion of 'preferred reading' where the producer of a text designs it with certain meanings in mind and hopes that the audience will decode them in a way which ties in to hegemonic beliefs. Writing in favour of 'oppositional reading' as a stimulating approach to interpreting advertisements, Myers (1983: 214-216) cited in Mick and Politi (1989: 5) contends:

There is a danger in the analysis of advertising assuming that it is in the interests of advertisers to create one "preferred" reading of an advertisement's message. Intentionality suggests conscious manipulation and organization of texts and images, and implies that the visual, technical and linguistic strategies work together to secure one preferred reading of an advertisement to the exclusion of others [...] 
The openness of connotative codes may mean that we have to replace the notion of "preferred reading" with another which admits a range of possible alternatives open to the audience.

Although the meanings generated at this level may be 'small', using McCracken's (1987: 121) term, Mick and Politi (1989: 9) posit that such 'small' meanings are in no sense immaterial, for they 'provide a looking glass on the role of personal history, self-esteem, fantasies, aspirations, doubts, fears, and other individual factors which contribute to ad-imagery interpretation'. This viewpoint underlies the nature of the analysis and discussion carried out in this study. Close attention is paid to the codification of meaning in the discourse in relation to cultural rules and social forces in the context of the situations in which the signs in the GSM advertisements are produced and received.

Thus, our analytical approach in this study falls within the purview of social semiotics where attention has been given to the role of the reader in the meaningmaking process. Social semiotics is based on the assumption that signs and messages must always be situated within the context of social relations and processes, as the same text may generate different meanings for different readers. Thibault (1991: 1) summarizes this view saying:

In social semiotics, the basic logic is that of contextualization. No semiotic form, material entity or event, text, or action has meaning in and of itself. The meanings these have are made in and through the social meaning-making practices which construct semiotic relations among forms, material processes and entities, and social actions.

\section{Colour and its Functions in Nigeria's Telecom World}

The visual content and design of advertisements generally find expression in the choice of colours advertisers make while trying to appeal to the audience. Beyond such aesthetic motivations, colours could assume another level of significance relative to the world being depicted. We must, however, admit that analyzing the semiotics of colour across cultural boundaries is no easy exploration. This is born out of the fact that different cultures classify and even perceive colours differently, even though colours are constant everywhere in the world. Thus, the meaning potential of colour is tied to the cultural world of the transmitters and the receivers. For instance, while the colour black often stands for death in western society, its opposite white symbolizes death in eastern cultures. In Japan, for example, white flowers are a reminder of mourning and death. Lindberg (2002 - 2005: 2) quotes Eco as saying:

When one utters a colour term one is not directly pointing to a state of the world [...], but, on the contrary, one is connecting or correlating that term with a cultural unit or concept. The utterance of the term is determined, obviously, by a given sensation, but the transformation of the sensory stimuli into a percept is in some way determined by the semiotic relationship between the linguistic expression and the meaning or content culturally related to it.

For our present purposes, the complexity in the signification of colours is evident in the deployment of certain colours by advertisers of GSM networks to carve an identity for their respective companies. In this regard, Caivano and Lopez (2007: 4) argue that:

One of the factors that renders the identity of an institution visible is colour. As a factor of identification of a company and, in turn, as a factor of differentiation from its competitors, colour is widely acknowledged in institutional design [...] 
it is one of the vectors of corporate identity. By mentioning cases such as IBM (the 'Big Blue'), we must agree that, inside the global semiotic system, colour is one of the key elements in the conformation of corporate identity. Its visual impact, pregnancy, memorability, as well as its possibilities of reproduction in different applications and media, are key factors in design.

It is in the light of this argument that we will discuss the use of colour for identity purposes and its attendant local connotations in the present discourse.

Yellow has come to be identified with MTN advertisements to such an extent that it has become a dominant signifier in the MTN world. At the connotative level of meaning, the use of the colour could be tied to any of the following representations, as put forward by the Glidden paint company: 'Yellow is truly joyous and virtuous in its purest form. Yellow exudes warmth, inspiration and vitality, and is the happiest of all colours. Yellow signifies communication, enlightenment, sunlight and spirituality. ${ }^{3}$ While all of these interpretations seem to fit into the telecom world, there are, however, yet other shades of meaning which coincide with the above interpretations or further extend them within the context of use.

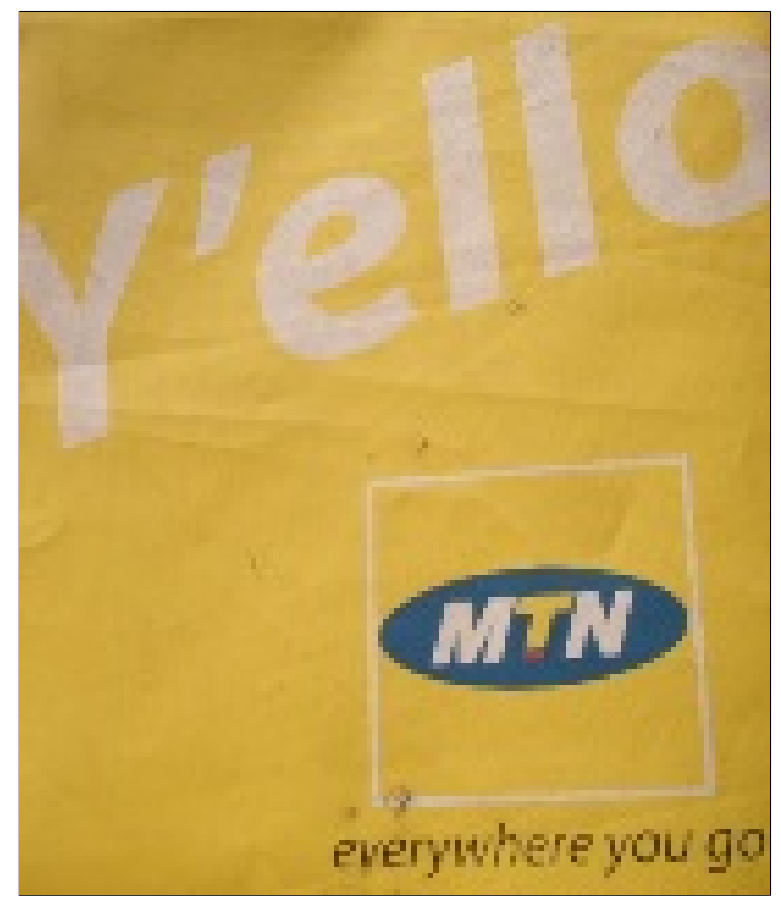

Figure 1. MTN Y'ello Signifier.

In order to create the impact of novelty so that attention is drawn to the colour trademark in a most arresting manner, the advertisers of MTN services have resorted to the use of the neologism in the nonce-word y'ello as shown in Figure 1. This signifier serves some rhetorical functions in MTN adverts. In answering phone calls, the ritualistic opening formula is hello but in MTN adverts, y'ello has been substituted for hello. Apart from the humorous stroke it has added to answering phone calls, the propagation of the 'MTN tongue' creates the impression that the universal language of communicating is being supplanted by MTN, thereby giving the impression MTN is the network which cuts across ethnic, regional and racial boundaries and is, therefore, dominating the scene and setting the pace in terms

\footnotetext{
3 'The Language of Advertising' by Peter Sells and Sierra Gonzalez. Available at http:// www.stanford.edu/class/linguist34/Unit_11/index.htm. Retrieved 5th May 2007.
} 
of coverage and efficiency. In fact, y'ello is so central to the MTN world that it is referred to as 'the language of possibilities' in one of the commercials.

In another sense, the greeting formula y'ello is a symbolic sign that creates an atmosphere of celebrations and merriment during festive seasons. For instance, during Christmas, the compliment people give one another is 'Merry Christmas/Happy Christmas' but in an MTN commercial, the parody reads: " $Y$ 'ello Christmas" as a season's greeting to all Nigerians and MTN subscribers in particular. This departure from the convention is rhetorically significant. It is a message of love in which MTN shares the joy of the season with its (intending) subscribers. It also suggests that the Christmas season is one during which making contacts with relations, friends and well-wishers is made stress-free when connected to MTN. As such, one could conveniently exchange love messages, greetings and give compliments without having to travel long distances. This signifier becomes particularly instructive when one notes that Nigerians who work and live in the cities usually return to their towns and villages to celebrate the joy of the season with their loved ones. One most disturbing concomitant to such extensive journeys during Christmas is the increase in the number of road accidents. Wishing the people " $Y$ ' ello Christmas" is an invitation to rely on MTN services in the bid to reach families and relatives and avoid the risk involved in embarking on ritualistic Christmas journeys. It seems, therefore, that one could understand why y'ello is actually referred to as 'the language of possibilities' for it is possible for people to share the joy of a festive period with their loved ones without necessarily being with them physically.

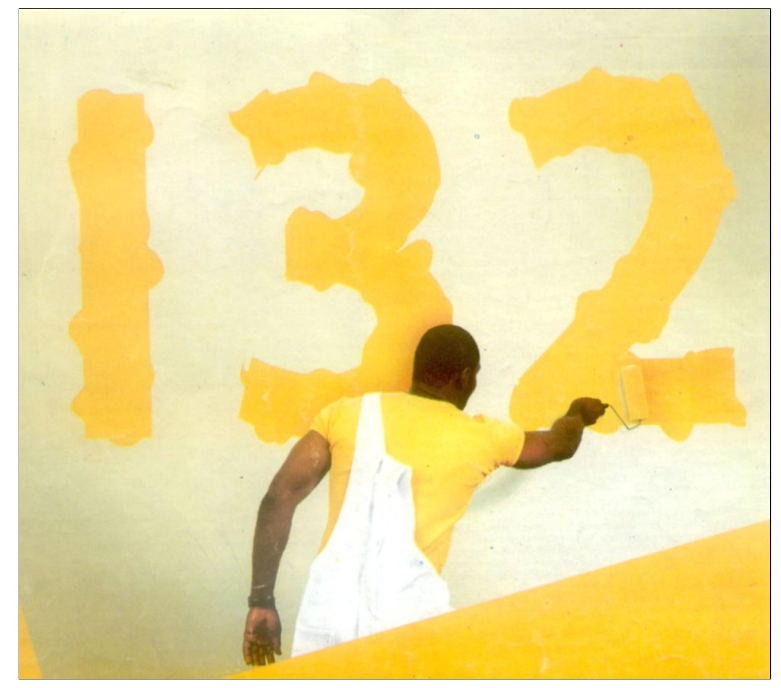

Figure 2. 'MTN Man' propagating the Y'ello message.

Still deploying the y'ello signifier, the company uses a product character popularly known as 'the MTN man'. He is commissioned in the commercials to transmit the y'ello message from cities to towns and villages, as he paints billboards and demarcates highways with the colour yellow to signify the connection of such locations to the MTN network. One intriguing aspect of the advert is the " $y$ ' ello magic" signifier as reflected in two major codes.

In the first one, the MTN man is painting a billboard with the colour yellow and as passengers in a vehicle passing by alight to greet him, the original colours of their vehicle and the clothes they wear automatically change to the colour yellow. There is also the case where the MTN man and his co-painters are trying to cross a river in the course of their mission and the yellow paint inside the container they 
are carrying accidentally spills into the river and the whole river turns yellowish at once.

This scene could remind one of the Biblical account recorded in Exodus 7: 19 where Moses performed the miracle of turning the waters of Egypt into blood when he was commissioned by God to lead the Israelites out of captivity in Egypt. Rather than producing a negative effect as in the Biblical account, the spilling of the yellow paint into the river in the present discourse has positive connotations. The scene is suggestive of the spontaneity and the vastness of MTN network. All together, the two major codes of the MTN " $y$ 'ello magic" seem to bring to the fore the infectious attribute of the MTN network which objects, people and natural phenomena cannot resist but must respond to with a 'chameleonic' instinct.

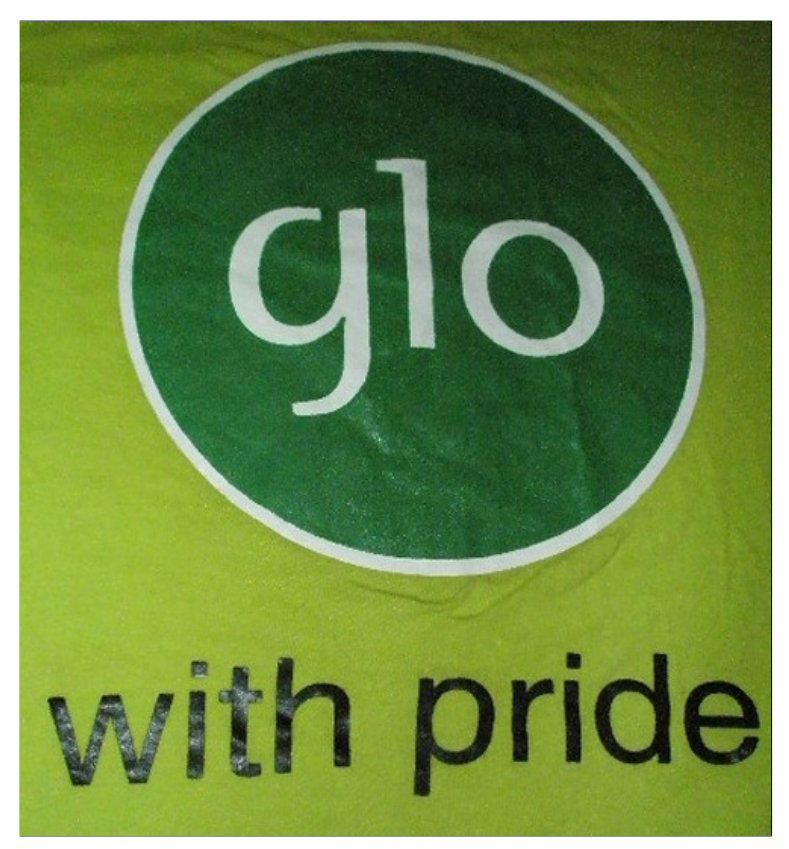

Figure 3. Globacom's Lemon-green colour.

Globacom's lemon-green assumes semiotic significance in very interesting dimensions, too. By hitting Nigeria's telecom market in 2003, when some other networks had already been in operation, Globacom needed to carve a niche for itself and the identification of the lemon-green colour with the company is symbolic: 'Green is the colour of life, and represents freshness, security and tranquility. Green creates an atmosphere that is calm and restful, and characterizes the intense power of nature'. In one of Globacom's memorable commercials, a satellite with a resplendent lemon green colour appears from the horizon and traverses a geographical space. Beholders of the lemon green satellite - the young and the old, male and female, professionals and artisans - are sent into wild excitement as they chorus the verbal semiotic surrogate "It's coming! It's coming! It's coming!" This verbal message helps to anchor the pictorial image by contextualizing it.

The sighting of the satellite and the attendant excitement call to memory the sighting of a new moon in a real life situation and what it signifies to people. In the Islamic world, for instance, the sighting of a new moon is a natural phenomenon pivotal to the Islamic calendar and religious activities. Across cultures, the appearance of a new moon in the sky signals a change of season to which diverse cultural 
and religious beliefs are attached. In a typical African village setting, the sighting of the new moon announces a joyful season, especially to children, and when it is full-blown, it rules the night, dispels darkness, and allays the fear and uncertainty characteristic of nightfall. It is the season when they can defy the night and sit in the full glare of the moon to enjoy moonlight tales from an elderly story-teller. The excitement of the children-audience here is akin to that of those sighting the lemon-green satellite which signifies the birth of Globacom.

In particular, the manner in which the beholders of the satellite get stupefied needs to be critically examined. People form diverse professional backgrounds such as engineers working at sites, medical practitioners attending to patients, and footballers playing a competitive match, all suspend their primary assignments at critical stages -- for instance when a footballer is about to score an all-important goal -- just to catch a glimpse of the satellite. In another case, it could be a wedding reception where the couple and their well-wishers are basking in the euphoria of the moment. Even at the point of taking a snapshot on such a memorable occasion, the bride, to the chagrin of on-lookers, would take a leap from the gathering in the direction of the satellite and others in admiration follow suit, momentarily abandoning the purpose for which they are gathered. Generally, their kinesic posture of maintaining a fixed gaze on the roving lemon-green satellite is significant. It implies the arresting power of the Globacom network which appears to have shifted people's attention away from already existing networks.

As a mark of Globacom's identity, the lemon-green colour becomes a symbol for the efficiency and dependability of the company, as expressed in the popular slogan 'Glo with pride'. 'Glo' in this slogan could be an abbreviated form of the name of the company, thereby suggesting that subscribers should take pride in using the Globacom network. Aside from this, the word seems to be an orthographic deviation from the verb 'glow'. Just as the lemon-green colour glows wherever it appears, the impression is created that the services offered by Globacom in the places covered by its network make the subscribers stand out from the users of other networks. This is also suggested in the popular advertising slogan 'Wherever you go, we glo', suggesting that the network outshines others in getting people connected.

Generally, the centrality of colour to the ads by these GSM service providers is underscored by Eliott (2005: 1):

One great thing about colour, agues Martin Lindstrom in his newly published marketing book Brand Sense 2005 is that it contributes to the 'smashability' of a brand. Successful brands can be 'smashed' like a glass of bottle of Coca-cola and consumers would still recognize the brand from its pieces. Logically, then, marketers should place a 'signature' colour at the center of all branding efforts.

In a similar vein, Caivano and Lopez (2007: 4) have this to say:

Colour has a high influence on institutional communication because it is perceived more quickly than other institutional symbols such as iconographies or verbal texts. It has been proved that colour requires less time of 'reading' than a logo. When shape and colour are adequately associated, colour (the more primary element) facilitates the memorability of the shape. Chromatic logos are more easily remembered than achromatic ones. In this way colour works as a factor for remembering the brand. For instance, Kodak yellow, Nestle red, Intel Blue, Coca Cola red, etc.

And this appears to be exactly what the network service providers have done with their preference for certain colours that have come to be identified with such companies and are central to their branding efforts. 


\section{Deictic Verbal Signs and Cultural Units in Nigeria's Telecom World}

In view of the fact that the issue of network coverage is carefully considered before people subscribe to the services of a telecom company, every service provider boasts of wide network coverage. This is evident in their commercials where spatial deictic markers are deployed to influence consumer behaviour:

MTN wherever you go

Wherever you live, wherever you work, wherever you play, we live everywhere you live (Glo)

The advertisers' predilection for the use of the deictic markers 'where', 'wherever', and 'everywhere' is predicated on the fact that they want to give the impression that they are capable of connecting urban centres to the rural areas, as subscribers living and working in urban centres would wish to keep in touch with people back at home in the hinterland. To further emphasize the mobile service providers' bid to connect the urban to the rural, spatial deictic markers are reinforced with non-verbal indexical surrogates. Such indices revolve around diverse cultural units such as occupations for which rural communities are noted. The occupations touch on cattle rearing, fishing/fish smoking, garri (cassava flour) processing, hand weaving, tying and dying of textile materials, farming with crude implements such as hoes and cutlasses, pounding with mortar and pestle, harvesting of palm fruit, among others. Apart from cultural units in the form of occupational engagements, there are pictorial images in the form of landscapes, showing thatch roofs, deserts, forests, creeks, and so on.

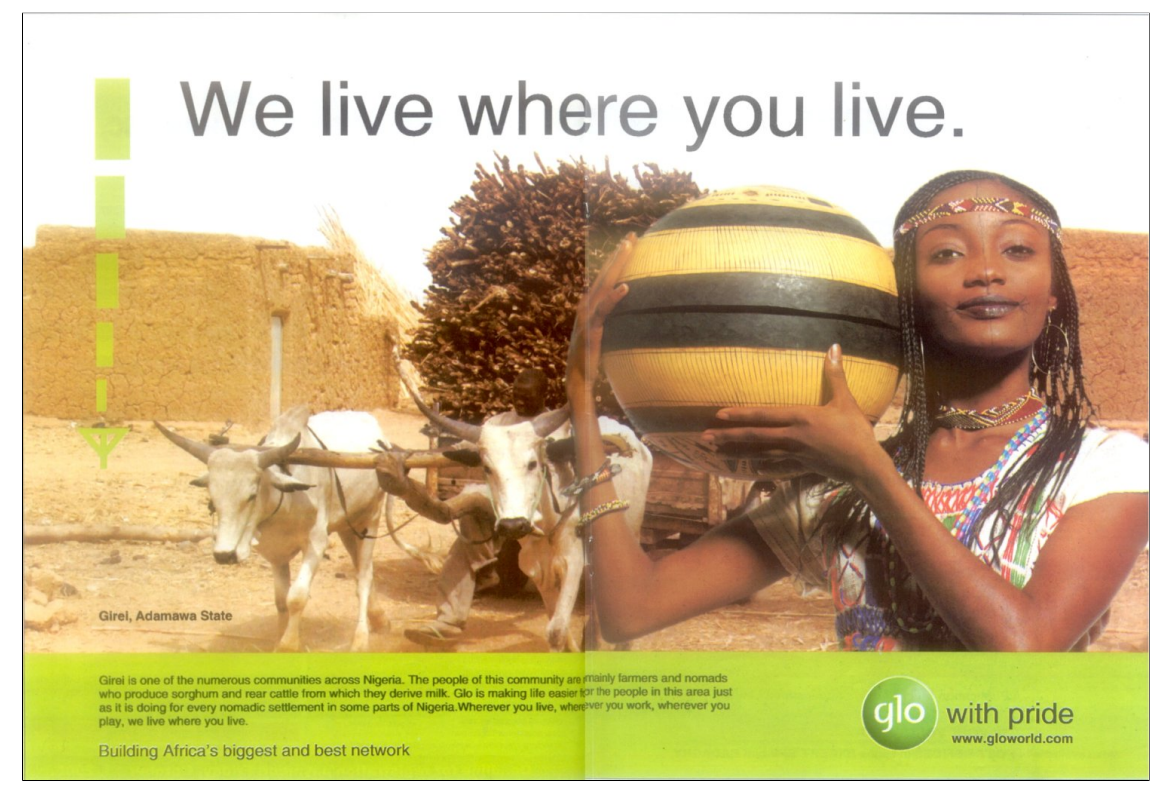

Figure 4. A typical Hausa-Fulani village setting in northern Nigeria.

In Figure 4 above, we see the pictorial image of a hut that is normally found in a village in northern Nigeria. Besides, there are yoked oxen transporting harvested grain stalks. There is also the pictorial image of a typical Hausa-Fulani girl decked in traditional attire. In Figure 5, two Igbo men wearing their traditional caps are relaxing in the village, as we see in the background the thatch roof of the hut and the thick forest. All of these signifiers help to arouse the emotions of the audience by 
appealing to their sense of pride in cultural images and traditional settings whose memories they would cherish and long to keep in touch with partly by using the network that connects them to such places. It is instructive to note that the artisans involved in the occupations we earlier cited are normally found in local communities. In the present discourse, they serve as iconic signs of the supposed ordinary people in rural areas who are connected to mobile networks and can therefore still keep in contact with their children and relatives living in towns and cities. Another implied message in this respect is the attention drawn to the affordability of mobile services by rural dwellers unlike time past when the telephone used to be a status symbol for the elite.

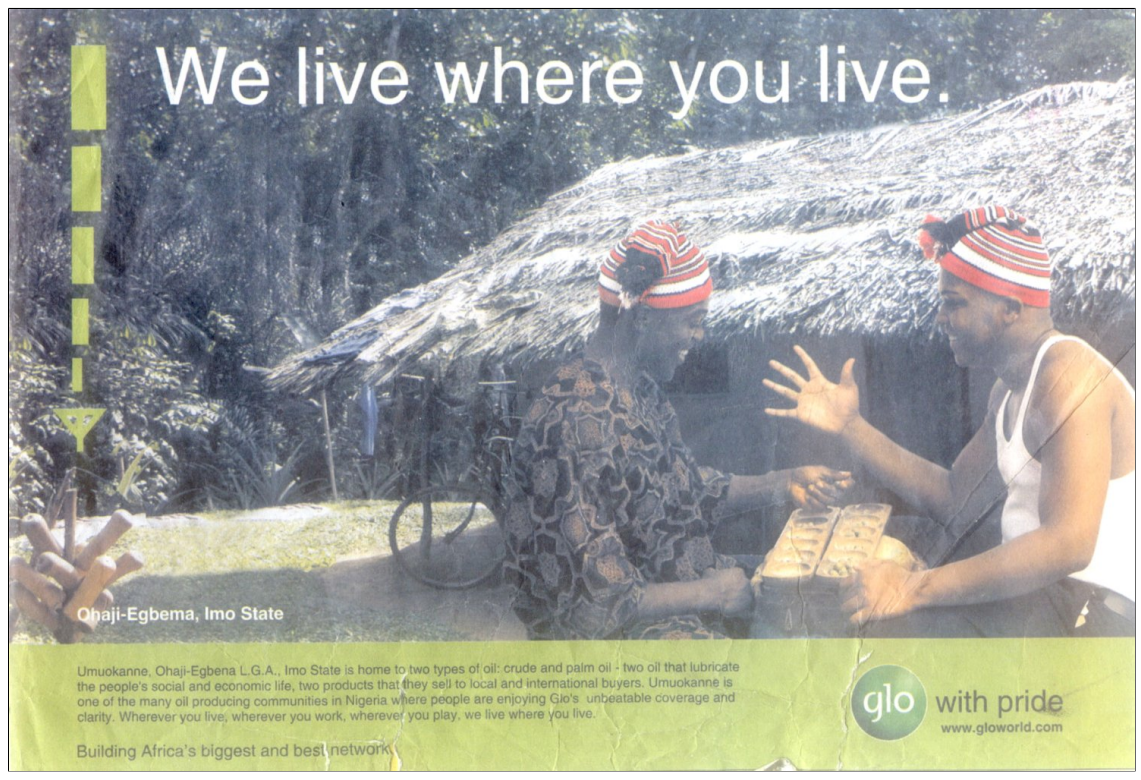

Figure 5. A typical Igbo village setting in eastern Nigeria.

Nevertheless, we have to point out that the preponderance of the spatial deictic forms 'everywhere', 'where', and 'wherever' in the discourse betrays the exaggerative bias of advertising discourse. In fact, there are numerous towns and villages not connected to any mobile telecom network and yet the service providers claim to be everywhere. This claim leaves a gap in the communication process, as the advertisers say that which would normally interest the audience in such a slippery arena of meaning. Such words, which are characteristically injected into the advertising discourse, are referred to as weasel words. According to Taflinger (1996: 4) weasel words are: '.. those words that are tossed into a sentence that change the actual meaning of the sentence while leaving an impression that is not different. It is the easiest way of not having to take responsibility for anything you say, or seem to say.'

Other cultural traits apart from the ones we examined earlier serve as useful sign vehicles in the discourse. Worthy of mention is the celebration of birth in a typical African society which has been made a dominant signifier in the telecom world. Normally, when a new baby is born to a family, the joy is shared with other members of the family both far and near. However far or near such family members may live, delivering such good tidings through mobile networks enhances promptness and efficiency.

In an MTN commercial set in the northern part of Nigeria, a grandfather who is about to attend the naming ceremony of a granddaughter cannot make it to the 
venue because horse riders in front of an Emir's palace are blocking the road, rendering the route impassable. Left with no other option when the baby's father calls that all is set but for his non-arrival, he has to communicate the name of the baby, Aishat, by phone and that settles the anxiety of either postponing the ceremony or depriving the grandfather of his customary responsibility. Commenting on the relevance of the message of the advertisement, Obinna Ezeobi says in a newspaper column that the advertisers seek to communicate: '...the fact that the network makes life easy, by connecting its subscribers with their loved ones, even when unforeseen circumstances hold them back and disrupt their plans...,

Also worthy of attention is the popular MTN commercial 'Mama Na Boy' in which a man blessed with a new born baby calls his mother in the village that his wife has been delivered of a baby boy. Expectedly, the mother receives the message with overwhelming joy amidst rigorous dancing. While the mainstream audience may not question the choice of announcing the birth of a baby boy in the commercial rather than that of a baby girl, the progressive audience may query the rationale for this choice and wonder why the commercial has not read 'Mama Na Girl'. This is the worry that two Nigerian lawyers, Adejoke Babinghton-Ashaye of the Centre for Public Policy and Research, and Felicitas Aibokun of Legal Resource Consortium have about the MTN 'Mama Na Boy' advert:

Viewed against the context of a strongly patriarchal society, in which male child reference is a fact, often leading to discrimination against the girl child and therefore against women, the campaign is inappropriate... Son preference is traditionally rooted in Nigeria and is based on social constructs of the role and value of males and females. Boys are valued at birth while... mothers are blamed for producing girls. ${ }^{6}$

From the foregoing, one could deduce that while the advertisers tend to project birth as a cultural unit worthy of celebration, they probably fail to take cognizance of the emotive associations it may invoke in some receivers of the message. It suggests, therefore, that how a message is interpreted depends on who the receiver of that message is. It is in this light that Eco (1976: 152) explains:

In exchanging messages and texts, judgements and mentions, people contribute to the changing of codes. This social labour can be either openly or surreptitiously performed; thus a theory of code-changing must take into account the public reformulation of sign-functions and the surreptitious code-switching performed by various rhetorical and ideological discourses.

Generally, the discourse of marketing mobile telecom services features cultural phenomena that range from traditional attires, musical instruments, traditional dance to masquerade performance during village festivals. Others include traditional transportation system involving the use of boats in coastal areas, bicycles used mostly in villages in eastern Nigeria, and horses and donkeys used in the northern part. One interesting thing about the commercials in which the cultural units are used as sign vehicles is that advertisers explore the cultural units across the major ethnic groups as shown in Figure 6 where traditional attires from different cultural backgrounds are showcased with the map of Nigeria placed at the centre. The strategy of exploring cultural units makes the commercials suit the het-

\footnotetext{
${ }^{5}$ See “"Crazy' World Cup Advertisements" by Obinna Ezeobi in The Punch Wednesday June 28, 2006, p. 37.

${ }^{6}$ Tell Magazine January 31, 2005, p.39.
} 
erogeneous Nigerian society, thereby giving the impression that their networks are capable of mitigating ethnic conflicts that have been the bane of Nigeria's unity. At another level of interpretation, the diffusion of cultural values in the discourse is a rhetorical attempt at provoking the cultural sensibilities of the audience in a bid to promote those aspects of the people's culture that have been suppressed by western cultural influence.

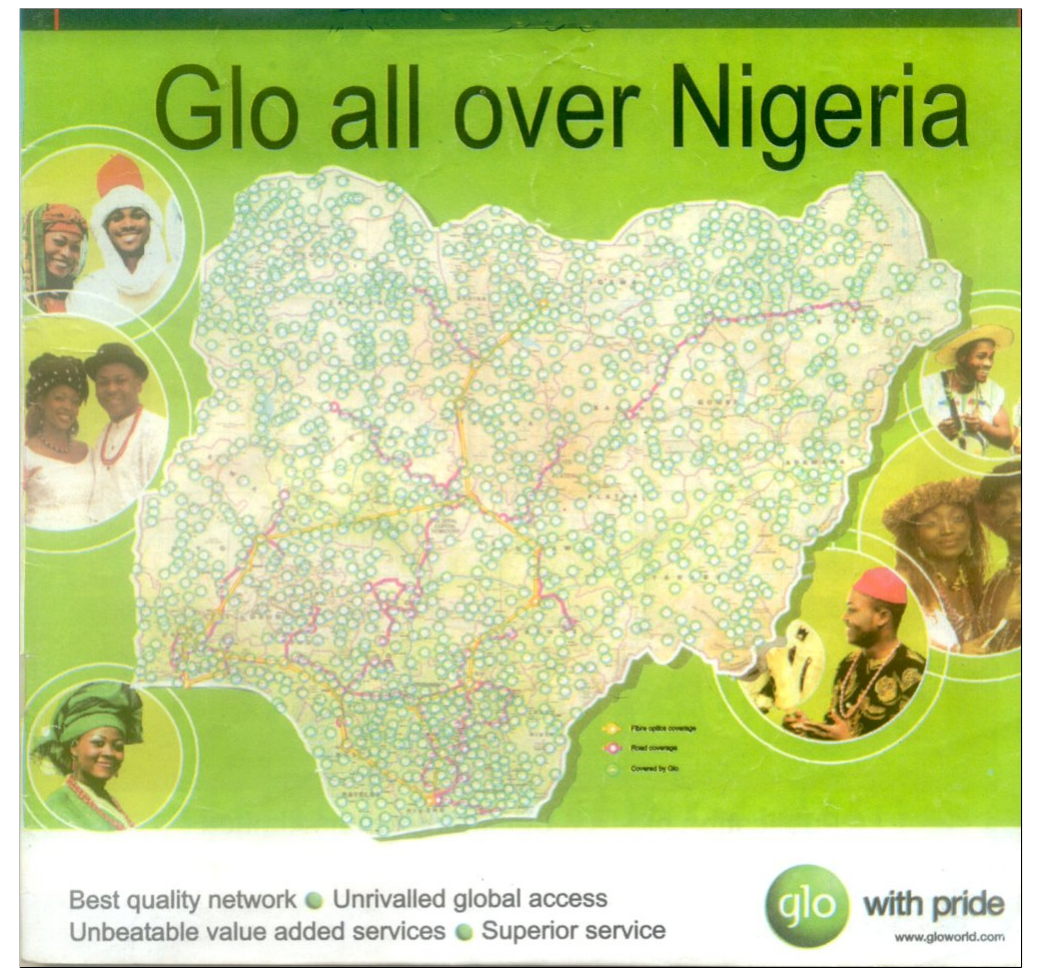

Figure 6. Traditional attires across the major ethnic groups in Nigeria.

Finally, the place of the temporal deictic marker 'now' in the discourse of advertising mobile networks deserves critical study. Consider the following excerpts:

\section{Econet NOW in ASHAKA}

Abakaliki... now on the network of the people (Glo)

Katsina now live on the network of the people. Come glo with me

Here, the emphasis is laid on the present time which marks a clean break from the past when the inhabitants of the geographical locations in question had no access to telephone services at all or when they used to experience disappointments and delays occasioned by poor telecom service delivery. In fact, the implied juxtaposition of the time past (then) and time present (now) in this case brings to bear the then-now dichotomy in popular discourses. Such a dichotomy could positively emphasize movement from obscurity, bondage or ignorance in the past, to limelight, freedom or knowledge in the present. The popular parlance 'Once I was blind but now I see' in Christian doctrine best captures the message that the unpleasant past should be swept into oblivion to celebrate great developments and achievements in the present.

At another level of interpretation, the temporal deixis 'now' underlines the rolling out of certain services by the telecom companies to satisfy the curiosity of 
their subscribers. The expression 'Now you can pay per second' in Glo adverts takes us to the kernel of a vexed issue in Nigeria's telecoms industry. At the inception of mobile telephony in Nigeria in 2001, major operators such as MTN and Econet Wireless were offering the per minute billing method such that a caller would have to pay for a whole minute regardless of the few seconds spent calling. Of course, subscribers did not take kindly to this perceived dubious business tendency as they felt the tariff should be based on the number of seconds spent.

Consequently, when Globacom broke the jinx in 2003 by introducing the per second billing, it was a great relief to its subscribers. We can, therefore, read the import of 'now' in the extract 'Now you can pay per second'. To further reinforce the verbal signifier 'now', there is interplay between verbal and visual signs. How it is instrumentalized here is interesting. In an advert, Charley Boy (Charles Oputa), a popular Nigerian musician, buys a banana from a hawker, peels just one, eats it halfway, returns the remaining half to the seller and collects change. The eaten portion of the banana is a symbolic sign for the number of seconds a subscriber could spend on the phone, while the returned uneaten portion symbolizes the remaining unused seconds which the service provider does not need to charge the subscriber for, hence the banana seller's resolve to give Charley Boy some change. Similarly, the money paid for the banana is a symbol for the subscriber's credit value which has to be deducted commensurate with the number of seconds used.

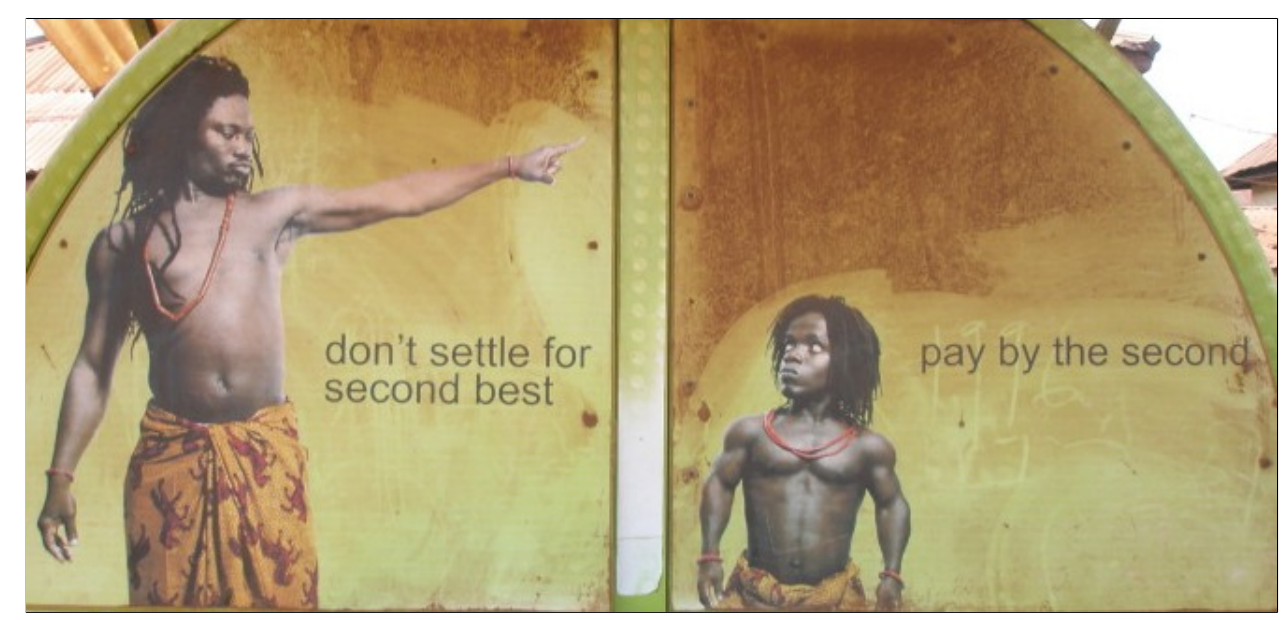

Figure 7. Daddy Showkey sending the copycat dwarf packing from the stage.

It is interesting that Globacom's trail-blazing effort of introducing 'pay per second' forced other competing service providers to start operating the system. Since it is a business world in which competition reigns supreme, Globacom sought to persuade subscribers that the originator of an idea or strategy is its repository and must be so acknowledged. In another Globacom advert, a dwarf musician comes to the stage and performs exactly the way a popular Nigerian musician, Daddy Showkey, performs. In terms of his dancing steps, hairstyle and costume, the audience would mistake him for Daddy Showkey but for his prominent physical deficiency in height. In no time, however, Daddy Showkey appears on stage, sends the copycat dwarf musician packing, and entertains the audience as the real figure known to the people generally. Then the advertisement is capped with the verbal surrogate 'glo the original pay by the second' or 'Don't settle for the second best'. Since the copycat dwarf musician, despite sharing some of Daddy Showkey's attributes, suffers a deficiency in height, he cannot be said to duplicate the original figure. 
By extension, Daddy Showkey is an iconic sign for the supposed Globacom's unparalleled pay by the second billing method, while the copycat dwarf musician is an iconic sign for the perceived low quality (counterfeit) pay per second billing method offered by other networks.

\section{Concluding Remarks}

The semiotic interpretations of the modes and contents of the commercials that we have carried out in this study are interesting in two major respects. In the first place, the images, colours and verbal pointers seen by the researcher-reader and the meanings derived from them strongly demonstrate the polysemic nature of signs. Signs, we must emphasize, are open to interpretations which are dependent on the cultural and experiential knowledge of the interpreter within a specific context of use. The representations we have made in the analysis would, therefore, not in any way foreclose further signification.

Second, the advertisers' careful selection of those signs that will make the image of their networks fit into the perceived desires and expectations of the target audience is interesting. At the syntagmatic level, there are endless possibilities that characterize and define the telecom world, but advertisers make conscious choices at the paradigmatic level to favour the perceptual framework of their world. Creating an atmosphere of joy, celebrations, and a stress-free world of communication, advertisers give the impression that getting connected to their networks takes away worries, disappointments and frustrations occasioned by poor service delivery. However, subscribers could tell how many times they have been disappointed by poor services when calling and the frustrating response they would have is: 'The number you are calling/dialing is not available/reachable at the moment, please try again later'.

In a similar vein, the commercials are tailored towards reflecting the people's positive perceptions of life, reflecting only the bright side of life. As humans, we cannot gloss over the fact that there are some gloomy aspects of life for which the use of mobile telephony would be expedient. Making calls in emergency cases such as armed robbery, road accident, fire outbreak, sudden illness, among others, is apparently suppressed in the commercials, just to focus the preferred messages that the people are inclined to spreading and hearing. As a matter of fact, Nigerians make it a prayer point that shouts of joy shall not cease from their habitation and that their ears shall be impervious to bad news.

On the whole, our exploration of the sign systems in the discourse of marketing mobile telecom networks in Nigeria sheds light on the fact that patterns of meaning could be extended, reinvented or contested, as advertisements yield elaborate inferential interpretations when readers 'work' on them.

\section{References}

Caivano, Jose Luis and Mabel Amanda Lopez (2007) 'Chromatic Identity in Global Markets: Analysis of Colours in Branding'. Colour: Design and Creativity 1 (1) : 3, 1 - 14. http://www.colour-journal.org/2007/1/3/07103article.pdf Retrieved 10th January 2008.

Chandler, Daniel (1994a) 'Semiotics for Beginners: Denotation, Connotation and Myth'. http://www.aber.ac.uk/media/Documents/S4B/sem06.html Retrieved 28th December 2007. 
Chandler, Daniel (1994b) 'Semiotics for Beginners: Strengths of Semiotic Analysis'. http://www.aber.ac.uk/media/Documents/S4B/sem10.html Retrieved 28th December 2007.

Eco, Umberto (1976) A Theory of Semiotics. Bloomington: Indiana University Press.

Eliott, Charlene (2005) 'Colour TM: Law and the Sensory Scan'. MC Journal. Vol. 8, Issue 4. http://www.journal.media-culture.org.au/0508/06-elliott.php Retrieved 10th March 2007.

'Exodus'. Holy Bible (King James Version). Cambridge: Cambridge University Press.

Leiss, William, Stephen Kline and Sut Jhally (1990) Social Communication in Advertising: Persons, Product and Images of Well-Being (2nd edition). London: Routledge.

Lindberg, Peter (2002-2005) 'Colors, Semiotics, and Constrained Universes of Expression'. http://www.tesugen.com/archives/03/12/colors-semioticsand-cues Retrieved 30th July 2007.

McKeown, Ruth (1998) 'A Semiotic Analysis of Two Ads for Persil Liquid'. http:/ /www.aber.ac.uk/media/Students/rum9501.html Retrieved 20th April 2007.

Mick, David Glen and Laura G. Politi (1989) 'Consumer Interpretations of Advertising Imagery: A Visit to the Hell of Connotation' Interpretive Consumer Research, ed. Elizabeth Hirschman. Provo, UT: Association of Consumer Research, 85-96.

'Nigeria - Mobile Market - Overview and Statistics' http://www.lxcomm.com/lxtelecommunications-research-toc.asp?toc=2998 Retrieved 10th May 2007

Punch. Wednesday June 28, 2006, p. 37

Pym, Anne (2003) 'Words Gone Mad: The Power of Naming in Oral Tradition'. Context: Journal of Social and Cultural Studies. Vol. 6, No 2. pp. 15 - 30.

Sells, Peter and Sierra Gonzalez ( n.d ) 'The Language of Advertising'. http:/ /www.stanford.edu/class/linguist34/Unit_11/index.htm Retrieved 5th May 2007.

Taflinger, Richard F. (1996) 'The Power of Words: Advertising Tricks of the Trade'. http://www.wsu.edu:8080/ taflinge/tricks.html Retrieved 10th January 2007.

Tell Magazine No. 5, January 312005. 